\title{
A CRIANÇA INTEGRAL E AS TEORIAS DO DESENVOLVIMENTO*
}

\author{
Alberto Olavo Advíncula Reis ${ }^{1}$
}

\section{RESUMO}

A confrontação das teorias do desenvolvimento psicológico, propostas por Jean Piaget e Henri Wallon respectivamente, enseja a possibilidade de se discutir o limite e o alcance dessas teorias na apreensão mais global, holística, da criança. Não se trata, neste artigo, de superar, como o faria um ensaio orientado fenomenologicarnente, os limites próprios a toda e qualquer redução teórica, mas, antes, de compreender a articulação teórica passível de garantir uma compreensão mais global da criança e do adolescente em desenvolvimento.

O cotejarnento das teorias desses dois autores marcados por semelhanças, amizade, trocas, mas, igualmente, por diferenças instigantes, propicia ocasião para que se pense sobre o modo fundamental como são concebidos e o lugar que ocupam os diferentes registros do desenvolvimento psicológico humano: o biológico, o mental e o social Apesar dos interesses divergentes que ambos pesquisadores manifestaun no tocante aos próprios sujeitos - Piaget interessando-se, exclusivamente, pelo sujeito epistêmico, estudando as leis subjacentes ao desenrolar do desenvolvimento cognitivo, enquanto Wallon interessava-se pelo sujeito psicológico, interrogando-se sobre o grande embate entre o social e o biológico nos processos de transformação da totalidade da criança -, ambos farão referências às mesmas dimensões do desenvolvimento

Entretanto, se a afetividade, enquanto se revela como uma dessas dimensões, é entendida por Piaget apenas como uma energética da ação sem poder ocupar nem um lugar preponderante no curso do desenvolvimento e nem desempenhar um papel estruturante do mesmo, bem diferente será a concepção de Wallon.

A emoção, forma larvária da afetividade, ocupará na concepção walloniana do desenvolvimento uma posição central, posto que será dela a função elementar de conectar o bebe, mergulhado em sua impotência orgânica, ao seu meio humano. A unidade criança-meio humano será uma unidade de partilha emotiva. E a partir dessa relação, anterior com o social, que a criança dirigir-se-á, em seguida, para o mundo dos objetos, instalando-se, só então, no interior de uma lógica sensório-motora. Para Piaget, a indistinção das dimensões sociais e físicas na sua compreensão do mundo objetal, isto é, do meio em relação ao qual a criança tentará se adaptar, Ihe permitirá descrever uma trajetória distinta. Com efeito, o biológico é considerado, por este pesquisados, como o ponto inicial de todo desenvolvimento e o social como o ponto final, sendo o mental o processo mediano entre esses dois estados. Tanto desta posição quanto do inegável privilegiamento dado por Piaget à observação dos reflexos exteroceptivos (que, para ele, são os exercícios reflexos da primeira sub-etapa do nível sensório-motor), decorre o falo dele ter a concepção de uma criança que liga-se, primeira e diretamente, ao mundo dos objetos físicos e que a partir da ampliação deste universo físico descobre o mundo social.

Não há grande sentido em repetir as indagações sobre o maior ou menor espaço concedido ao registro do social, do afetivo, do lógico ou do cognitivo em outra teoria. A questão que se pode colocar é a de saber em que dimensão tais registros se articulam, visto que a ordem desta articulação, e não o cômputo dos elementos em jogo, permitiria uma aproximação mais completa e global da criança em desenvolvimento.

Palestra proferida por ocasião da participação em mesa-redonda sobre “Crescimento e Desenvolvimento” no âmbito do Enconrro Sobre Creches, promovido pelo CDH e pela Faculdade de Saúde Pública da USP, na cidade de São Paulo, em outubro de 1986.

1 Professor assistente do Departamento de Saúde Materno-Infantil da Faculdade de Saúde Pública da USP. 


\section{INTRODUÇÃO}

Quando se aborda a questão do desenvolvimento psicológico percebe-se, de chofre, urna situação dilacerante: a criança é apreendida de forma fragmentada, puxada pelos quatro cantos das teorias. A essa necessária fragmentação, exigida pelos diferentes reducionismos teóricos, opõe-se a necessidade de uma apreensão e de uma percepção global, holística, da criança em desenvolvimento, necessidade sobretudo presente para aqueles que fizeram da criança seu objetivo de trabalho e cuja prática cotidiana, voltada para ela, não pode e não deve prescindir de uma compreensão teórica.

O intuito, aqui, é o de discutir a concepção básica da teoria do desenvolvimento piagetiano a fim de aclarar um pouco o caminho da possível compreensão da criança como fenôrneno mais global. Para tal, tentar-se-á, sem aprofundar no detalhe das teorias, cotejar as concepções de Piaget e de H. Wallon acerca do processo de desenvolvimento infantil. Este procedimento e essa tentativa justificam-se por bem mais de uma razao. Companheiros de viagem, amigos, debatedores, ambos construíram teorias acerca do desenvolvimento infantil, cujas semelhanças e diferenças têm-se revelado instrutivas e proficuas.

Naquilo que tango às semelhanças é mister fazer ressaltar tanto a perspectiva genética assumida por ambos bem como a utilização comum do método e observação clínicas.

Os pontos comuns existentes entre os dois pesquisadores sustentam-se tanto numa concepção da criança enquanto um ser fundamentalmente ativo que encontra, em suas trocas com o meio, $\mathrm{O}$ impulso para seu desenvolvimento, como na maneira pela qual concebem o processo infantil de construção psicológica ativa da realidade.

Os dois partilham da idéia da existência de uma dinamica propriamente dialética no processo de desenvolvimento, uma vez que assumem que a criança constrói e manipula a realidade em seu interior, em função da realidade exterior vivenciada, uma vez que essa realidade atua sobre a criança, impelindo-a a modificarse em um esforço de adaptação. Tais semelhanças, de caráter geral, prolongam-se na descrição dos estádios de desenvolvimento estabelecidos pelo psicólogo francês e pelo epistemólogo suíço (Tabela 1).

Tabela 1

\begin{tabular}{lll}
\hline \multicolumn{1}{c}{ Autores } & \multicolumn{1}{c}{ Estádios } & \multicolumn{1}{c}{ Características } \\
\hline Wallon & Criança senso-motora & 1. Descoberta do mundo dos objetos \\
Piaget & Criança senso-motora & 2. Atividade de esquemas sensoriais e motores \\
& & \begin{tabular}{l} 
3. $\begin{array}{l}\text { Inexistência de representação mental ligada à } \\
\text { cognição e à afetividade }\end{array}$ \\
\hline
\end{tabular} \\
\hline
\end{tabular}

\begin{tabular}{|c|c|c|}
\hline Wallon & Criança sincrétia & 1. Pensamento transdedutivo \\
\hline Piaget & Criança pré-operatória & 2. Insensibilidade à contradição \\
\hline
\end{tabular}

\begin{tabular}{|c|c|c|}
\hline Wallon & Criança categorial & 4. Caráter intuitivo e preconceptual \\
\hline \multirow[t]{3}{*}{ Piaget } & Criança operatória concreta & 1. Abandono do pensamento infantil \\
\hline & & 2. Expansão da razão \\
\hline & & $\begin{array}{l}\text { 3. Capacidade maior para conceptualizar adequadamen- } \\
\text { te e realidade }\end{array}$ \\
\hline
\end{tabular}

Wallon

Adolescente

Piaget

Adolescente operatório-formal
1. Capacidade de abordar o inatural - aquilo que não é realisticamente presente, que se encontra no futuro que não está na zona da experiência da realidade, mas no campo do possível 
No plano das diferenças, ressalta-se que enquanto Piaget interessa-se pelo sujeito epistêrnico, isto é, por aquilo que "há em comum nas estruturas intelectuais dos sujeitos de mesmo nível de desenvolvimento"² - enfatizando a continuidade ao longo do processo de desenvolvimento -, Wallon, por outro lado, entusiasma-se pelo sujeito psicológico, isto é, a ele interessam não os aspectos cognitivos "mas todos os aspectos que integram a personalidade do individuo em qualquer momento de seu desenvolvimento"3 - incluindo aqui aqueles aspectos que determinam essa personalidade de fora. Ao contrário de Piaget, ele insistiu mais nas descontinuidades e nas crises.

Tais argumentos legitimam as comparações entre os dois autores, fazendo assim avançar nossa compreensão acerca do desenvolvimento global da criança.

A preocupação fundamental de Piaget foi a elaboração de uma epistemologia genética que permitisse descobrir as leis gerais, subjacentes à cognição, à génese das funções cognitivas, e que lhe possibilitariam averiguar como se constrói o conhecimen o do ponto de vista evolutivo. Seu trabalho, deve-se enfatizar, nunca teve por escopo a abrangência da totalidade do objeto criança, mas cingiu-se à descrição das transformações do pensa nto infantil e ao estabelecimento das leis que regem essas transformações.

$\mathrm{O}$ estudo da génese da inteligência foi o instrumento pnvilegiado e necessário que tornou possível a realização secund ria do desejo de Jean Piaget de estabelecer um liame entre a biologia e a teoria do conhecimento. O limite e a grandeza do alcance de sua contribuição ao avanço do conhecimento psicológico da criança tem neste instrumento seu ponto de engaste; limite porque estudou parcialmente a criança, grandeza porque revolucionou genuinamente a maneira de compreende-la.

Resta, sem dúvida, se interrogar melhor sobre a natureza deste limite ou das condições que impuseram esta abordagem parcial da criança. De toda maneira, se a criança apreendida por Piaget pelo viés da cognição perr iitiu-lhe proceder a este deslocamento organicamente contínuo da biologia $\sim$ teoria do conhecimento diversamente, a criança que interessou a Wallon foi aquela que lhe propiciou o agenciamento das ciências naturais com as ciências humanas. Isto se tornou possível porque Wallon pode entendê-la como um ser que e essencialmente biológico ao nascer e se converte, pela ação social, em ser psicológico. Longe do espírito que ammou a pesquisa piagetiana referente a descrição das leis gerais da transformação do conhecirnento, Wallon pretendeu descrever os processos psicológicos que, sobre uma base biológica e em contato com o meio social, vão transformando continuamente a totalidade do ser da criança.

A compreensão da criança, enquanto um sistema global em desenvolvimento, impediu que Wallon privilegiasse um aspecto exclusivo ou uma dimensão preponderante de sua evolução. Propôs, ao contrário, um modelo onde a interação dos níveis biológico e social permite a construção de um Ego no qual se integram os aspectos cognitivos e os sociais, se resolvem os problemas intelectuais e os emocionais. Daí, foi-lhe possível descobnr como o recém-nascido tem acesso à emoção através dos intercâmbios sociais; foi-lhe possível situar a alternância entre os períodos em que a criança se encontra voltada para a construção do seu Eu (período emocional, período do personalismo) e aqueles outros perfodos em que ela se volve para a elaboração do mundo exterior (senso-motor, sincretismo).

Ajuriaguerra ${ }^{4}$ resumiu, em seu conhecido Manual de Psiquiatria, a descrição das etapas do desenvolvimento infanto-juvenil proposta por Wallon. Aquilo que caracteriza a criança ao nau cer é a importância da presença da atividade rnotora reflexa.

A resposta aos diferentes tipos de estimulação, quer sejam eles de natureza interoceptiva, proprioceptiva ou exteroceptiva, é sempre uma resposta reflexa. Esta resposta motora reflexa pode se apresentar de duas maneiras, ora como uma resposta relativamente adaptada a seu objeto (sucção, preensão, etc.), ora sob forma de grandes descargas impulsivas sem controle. Tais respostas "desadaptadas" se dão em virtude do falo de os centros corticais não estarem ainda aptos para exercer seu pleno controle sobre elas. Trata-se, neste caso, de uma forma de atividade matara arcaica muito próxima das crises convulsivas em que o controle superior encontra-se, temporariamente, abolido.

Ora, o primeiro estádio descrito por Wallon, denominado impulsivo puro, é caracterizado pelo papel nitidarnente dominante que esta atividade motora arcaica assume durante os primeiros me-

2 INHELDER, B. Las estratégias cognitivas: aproxi^lnación ai estádio de los procedimentos de resolucion de problemas.An. de Psic., 18: 5,197X.

3 PALACIOS, J. J. Piaget y H. Wallon: dos perspectivas distintas, un solo sino ve dadeiro. In. Mon, Inf. y aprend. 2: 200-205, 1981.

4 AJURiaguerRA, J. D. Manuel de Psichiatrie de l'enfant. 2a ed., Paris, Masson et Cie Editeurs, 1974. 
ses de vida. Por volta do sexto mês, entretanto, um novo tipo de conduta revela-se dominante, determinando o aparecimento de um segundo estádio. Surgem neste momento os primeiros sinais orientados em direção ao mundo humano. Tratase de condutas já presentes desde o terceiro e o quarto mês, tais como crises de cólera, sorrisos, entre outros, mas que se tornam dominantes por volta do sexto mês, quando, então, exprimem e definem, claramente, um certo tipo de relação com o mundo exterior.

A existência deste estádio emocional, ou ainda chamado de estádio de simbiose afetiva, opõe-se ao ponto de vista piagetiano na medida em que, para ele, a afetividade nunca é preponderante e nem pode ser organizadora em si. Em contrapartida, para outros autores que partilham de certas noções e princípios piagetianos (Spitz, 1968; Mahler, 1977), a descrição walloniana de um estádio emocional ou simbólica afetivo—que se constituiria como prolongamento da simbiose fetal e da si nbiose alimentar dos primeiros meses de vida — seria plenamente aceitável. De falo, tal estádio coincide com as idéias, de modo geral expressas por eles mesmos, de que são as satisfações das necessidades - ligadas ao fato de a criança ser alimentada, trocada, acalentada - que concorrem para o estabelecimento das primeiras relações humanas significativas por volta do sexto ou do oitavo mês. Neste estádio, com efeito, a criança, além dos cuidados propriamente materiais, necessita de manifestações especificamente afetivas, visto que é a emoção que domina todas suas relações. A criança estabelece lações afetivas de tal importância com seu meio que funda, com ele, uma unidade emocional, no interior da qual partilha o detalhe das mais diversas emoções de angústia, alegria ou gozo.

No término do primeiro ano, a criança orientar-se-á em direção dos interesses objetivos; descobrindo e situando-se num mundo de objetos. Trata-se do terceiro estádio denominado sensório-motor. Wallon sublinhará a importancia conferida a dois aspectos diferentes do desenvolvimento: a marcha e a palavra, ambos desempenhando um papel de primeira monta na renovação total do universo da criança.

De fato, com a aquisição da marcha, 0 espaço é completamente transformado pelas possibilidades novas de deslocamento operadas sobre ele. Por outro lado, com a aquisição e o uso da palavra articula-se a atividade simbólica, tornando possivel "a atnbuição de uma representação a um objeto e a alocação de um signo verbal a esta representação" 5 . Tanto as transforrnações ligadas à orientação da criança num mundo objetal, quanto as operações espaciais, como, ainda, a emerg^ancia da atividade simbólica, ocorridas por volta de um ano e meio e dois anos de idade, guardam toda semelhança descritiva com as últimas su etapas do estádio sensório-motor piagetiano.

Em suas primeiras publicaçôes, Wallon refere-se a um quarto estádio: o est fdio projetivo. Este estádio reveste-se de uma importancia particular (apesar de desaparecer dos escritos posteri res de Wallon), posto que é a ele que se liga toda a concepção genética walloniana da passagem do ato ao pensamento.

A criança, segundo Wallon (e Piaget), s6 conhece o mundo através de sua ação sobre ele. Durante este período - período projetivo - a criança se vê na necessidade de se projetar nas coisas para apreender a si própria.

A função motora é, assim, instrumento da consciência. Neste m cio de sua vida mental propriarnente dita, a criança deve ter seu aparelho motor à sua inteira e contínua disposição. $\mathrm{O}$ ato aqui é, verdadeiramente, acompanhamento da representação.

O pensamento é como que projetado no exterior pelos movimentos que o exprimem e se ele não for expresso, tanto em gostos quanto em palavras, ele não existe. Ele não subside sem essa projeção gestual.

O quinto estádio é o do personalismo. A criança consegue tornar-se independente das situações nas quais ela está implicada, isto é, consegue reconhecer sua personalidade própria independentemente das situações.

Ela se alça a uma "consciência de si" que sé é possível quando se é capaz de ter uma imagem de si próprio. Uma vez afiançada tal imagem, ou representação de si, a criança se afirmará nitidamente com o negativismo. Crise de oposição existente entre dois anos e meio e três anos.

$\mathrm{O}$ fato de a criança ter acesso, neste momento, a uma consciência de si é marcado por uma sensibilidade particular face à presença do outro sob forma de timidez e vergonha, o que entrava e bloqueia sua atividade e faz fracassar de maneira provisória sua adaptação.

Após este episódio de vergonha específica - cuja razão está no falo de que a criança, agora, tornou-se capaz de representar a si própria numa situação onde ela é vista por outrem, melhor dizendo, de se ver como o outro a vê - ela irá afirmar-se e experimentar todos os efeitos da afirmação de si. O essencial para ela constituirá em

5 AJURIAGUERRA, J. D. Op. cit. 
afirmar-se como um indivíduo autónomo e para isso todos os meios serão bons: afirmar-se se opondo e tornar-se travesso para chamar atenção são as mais banais reações da criança neste estádio.

Isto significa simplesmente que, tendo superado a fase de confusão com o outro, a criança agora quer ser reconhecida pelo outro. Este período importante para o desenvolvimento da personalidade normal começa pela oposição e termina pela sedução. Com o progresso do domínio motor, a criança que inicialmente afirmou-se se opondo pode agora se fazer admirar, se fazer amar, existir.

Esta tomada de consciência de si, entretanto, ainda é instável e frágil. Ela é ainda solidária da "constelação familiar", na qual a criança está integrada.

É com o início da escolaridade - seis anos - que a criança encontrará os meios intelectuais e as ocasiões para individualizar-se de maneira nítida É o estádio onde a criança diversificara seus laços, participará da vida de vários su grupos concomitantemente, ocupando papéis e lugares difi rentes. Wallon enfada a importância dessas trocas sociais.

a. Quando se confronta Wallon a Piaget no sentido d que esta confrontação serve para aclarar um e outro autor - percebe-se que a concepção piagetiana da criança é uma concepcã "quase solipsista”, ou seja, Piaget busca exclusivamente no iD divíduo os elementos da vida psíquica. É como se a criança, ti um Robinson Cruzoé que isolado em sua ilha fosse gradativamen te tornando-se apto a extrair diretamente de seu meio circulante a substância material e os instrumentos que o exercício do pensamento exige.

b. Sabe-se que foi, em parte, a partir das experiências com moluscos lacustres que Piaget elaborou sua noção de adaptação calcada nos mecanismos de assimilação e acomodação. Est noção é fundamental e central no processo do desenvolvimento psicológico e da inteligência (definido) como um processo dá equilibração, isto é, de adaptação móvel e estável entre o sujeito e o meio (inicialmente esse meio é o universo físico).

Ora, a primeira crítica que se pode então fazer é que est; concepção—urdida por Piaget a partir da observação de um; espécie biológica rudimentar, não social, como é o caso dos mó luscos lacustres Limae-não pode ser estendida, sem problemas ao ser humano que é basicamente 'social. Como bem observa Jalley (1979), ao criticar precisamente este aspecto de teoria pi\& getiana, o ser humano é um ser essencialmente social, possuindo características especificas, distintas de outros animais: pré-matu ração nervosa, imperí- cia neuromotora manifesta nas deficiência dos programas hereditários, restrição progressiva dos programa hereditários no curso da evolução filogenética, infancia prolonga da com grande espaço de tempo aberto à aprendizagem que virá suplementar sua carência biológica. Esta constelação de falos interdependentes implica em que no domo sapiens a adaptação dc sujeito ao objeto repousa numa adaptação anterior e mais precoce a adaptação do sujeito ao sujeito, do homem ao homem. Piage promove uma redução da adaptação do sujeito ao sujeito (que é uma relação intersubjetiva e primariamente humana) à adaptação do sujeito ao objeto.

Tem-se, é verdade, assinalado que tal crítica repousa, apenas, numa confusão terminológica posto que o termo objeto assume, no vocabulário piagetiano, uma acepcão de objeto físico e também uma acepção ligada ao social. Entretanto, torna-se absolutamente fundametal assinalar que, além das questões de pertinência e de origem acarretadas pela indiferenciação entre objeto físico e objeto humano, os dois tipos de relações decorrentes de uma tal distinção, a saber, adaptação do sujeito ao sujeito e adaptação do sujeito ao objeto, viabilizam e orientam linhas diferentes de construção do desenvolvimento.

Ora, da análise dos primeiros estádios do nível sensório-motor decorre que, para Piaget, a origem das categorias físicas, da inteligência, de toda relação ulterior com o mundo físico e social tem sua raiz nos reflexos exteroceptivos. Quando Piaget observa algumas reações em função do estimulo externo, conforme bem analisa Jalley, ele observa outras, tais como, gostas e atitudes dos braços, da cabeça e do tronco. "Estas reações desordenadas sem objetivo aparente, espasmos, agitações, gritos, aliás os mais frequentes no nascimento, serão aquelas a que Wallon dará maior importancia no curso do primeiro ano (impulsividade motoraemocional) enquanto Piaget as desprezará”.

Estes reflexos tónicos conectados com os receptores interoceptivos, e que expressam o nível de maturação nervosa própria dos seis primeiros meses, em si mesmos não se orientam no sentido de extrair do meio circundante qualquer tipo de substancia material. "Mas, falo absolutamente fundamental, (e ausente na teoria piagetiana) estes gostos, espasmos, estes reflexos tónicos expressam o desamparo do homo sapiens imaturo ao nascer".

Sua função biológica consiste em ser uma chamada de socorro: "elaboradas progressivamente em expressões emocionais, estas reações organizam-se em um sistema primitivamente de comunicação que precede a toda relação com o 


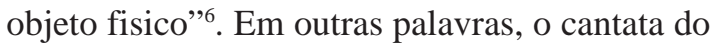
bebe com o social precede seu contato com o mundo físico (sensório-motor).

Enfim, a partir destes pontos, pode-se, então, dizer que Wallon considera o homem como um ser cuja organização biológica contém em sua própria estrutura a amálgama do social com o organizo; enquanto que a base do desenvolvimento mental piagetiano parece ser o indivíduo e suas relações com o meio físico organizados num sistema fechado.

O ser humano pelas suas especificidades biológicas (imaturidade biológica, por exemplo) é desde o início um ser voltado e votado ao social sendo que "a emoção é o verdadeiro substrato funcional que liga o sujeito ao outro e, através deste outro, ao mundo físico". Distanciado desta concepção de Wallon situa-se Piaget para quem são os exercícios funcionais reflexos que levam a criança a ligar-se diretamente ao mundo dos objetos físicos, sendo da ampliação deste universo físico que ela descobre e se estende ao social.

Entretanto, é bem conhecida a afirmação piagetiana de que todo fenómeno possui raízes biológicas e um término social, sendo que o processo entre estes dois estados é mental ou psicológico. Consequentemente, a questão que se coloca, em última análise, não é aquela de saber se

\section{BIBLIOGRAFIA}

EVANS, R. Jean Piaget, o Homem e suas Idéias. Rio de Janeiro, Forense Universitária, 1980.

JALLEY, E. Wallon, lecteur de Freud et de Piaget. Paris, ESF, 1981.

MAHLER, M.; PINE, F.; BERG MAN, A. O Nascimento Psicológico da Criança. Rio de Janeiro, Zahar, 1977.

PIAGET, J. Seis Estudos de Psicologia. 9a ed., Rio de Janeiro, Forense Universitária, 1978. diferentes teorias contemplam ou não diferentes dimensões do desenvolvimento, tornando-se, finalmente, uma teoria "mais completa" do que a outra. A verdadeira questão, e é somente neste sentido que se pode falar, efetivamente, de apreensão balística da criança pela teoria, é a de saber que lugar os diferentes registros ou dimensões do desenvolvimento ocupam no ambito de uma determinada teoria.

Assim, não se pode levar a sério, estritamente falando, que Piaget, por exemplo, ignora a dimensão social ou que desconhece o papel da afetividade no desenvolvimento humano. Mas é, precisamente, neste ponto que Jalley percebe 0 mal entendido que separa as concepções de Piaget e Wallon, visto que a série biológico-mental-social (raiz biológica, término social e processo psicológico intermediário) pode efetivamente ser aceitável se ela é compreendida dentro de uma perspectiva sincrônica, mas não se ela é colocada, como o faz Piaget, numa perspectiva diacrônica.

Ao contrapor estas duas teorias, pretendeuse apenas problematizar a questão da natureza das reduções teóricas que podem fazer obstáculo a uma apreensão global da criança como um ser biológico, social, cognitivo e emocional em desenvolvimento.
SPITZ, R. De la Maissance a la Parole. Paris, PVF, 1968.

WALLON, H.; PIAGET, J. y otros. Los Estadios en la Psicologia del Niño. Paris, Ediciones Nueva Vision, 1977.

WALLON, H. Psicologia e Educaçao da Infancia. Lisboa, Editorial Estampa, 1975.

ZAZZO, R. Henri Wallon, Psicologia e Marxismo. Lisboa, Editorial Vega, 1978.

6 JALLEY, B. Para una lectura comparada de Piaget y Wallon. In Mon Inf. y aprend. 2: 207-227, 1981. 